\title{
Colour removal using nanoparticles
}

\author{
Ravindra D. Kale* and Prerana B. Kane
}

\begin{abstract}
Nickel nanoparticles were synthesized and used to decolourize dye effluent. C. I. Reactive Blue 21 was taken as a reference dye, and polyvinyl pyrrolidone (PVP) was used as a stabilizer to prevent agglomeration of nanoparticles. Characterization of nanoparticles was done by a laser light scattering particle size analyzer, X-ray diffraction (XRD) analysis and transmission electron microscopy (TEM). Various parameters like $\mathrm{pH}$, dye concentration, nanoparticle concentration, alkali addition, salt addition and duration studied for dye decolourization. To confirm the attachment of degraded products of dye on the nanoparticles, FT-IR analysis was done. About $98 \%$ colour removal with simultaneous reduction in chemical oxygen demand (COD) was achieved.
\end{abstract}

Keywords: \% Decolourization, Nickel nanoparticle, Polyvinyl pyrrolidone, Effluent

\section{Background}

The effluent discharged from textile dyeing mill is a highly concentrated coloured wastewater and consists of a mixture of various dyes. Most dyestuffs are complex aromatic structures which are difficult to be disposed. Moreover, the colour in water resources poses aesthetic problem. They also cause serious ecological problems like significantly affecting photosynthetic activity of aquatic plants due to reduced light penetration and may be toxic to some aquatic organism (Zollinger, 1987).

Many methods used for dye removal include chemical coagulation, flocculation, chemical oxidation, photochemical degradation, membrane filtration and aerobic and anaerobic biological degradation. These methods have one or other limitations, and none of them is successful in complete removal of dye from wastewater (Dizge et al., 2008).

Metal nanoparticles are also employed for decolourization of the coloured effluent. The size and shape of the nanoparticles play an important role in the decolourization and can be controlled by various physical and chemical routes. These particles show tendency to aggregate and thus lower the activity. Hence, to prevent the aggregation irreversibly, researchers have coated the particles with low molecular weight polymeric compounds (Hergt et al., 2006; Naoki 2008; Sakulchaicharoen et al., 2010; Shen et al., 1999). However, the need for the non-

\footnotetext{
* Correspondence: rd.kale@ictmumbai.edu.in

Department of Fibers and Textile Processing Technology, Institute of Chemical Technology, Mumbai 400 019, India
}

agglomerated nanoparticles with a well-controlled mean size and a narrow size distribution is not yet achieved.

Tagar et al., (2012) have carried out reduction of dyes by using gelatine stabilized gold nanoparticles (GNPs). Nanoscale nickel particles (NiNPs) were used for decolourization of Congo red dye by Kalwar et al. (2013). Nickel oxide has also been used for oxidation of a wide range of organic compounds (Lai et al., 2007; Wang et al., 2008; Nateghi et al., 2012, Kalwar et al., 2014). In a study conducted by Saadatjou et al. (2008), 80 \% decolourization of dye basic red 46 was achieved using hardened pieces of Portland white cement as adsorbent. In a research conducted by Asgari and Ghanizade (2009), methylene blue dye could be completely decolourized after $2 \mathrm{~h}$ treatment time using $1 \mathrm{~g} / \mathrm{L}$ bone ash. Song et al. (2009) carried out decolourization of reactive dye using nickel oxide nano-sheets at acidic $\mathrm{pH}$ after $6 \mathrm{~h}$.

Among all the magnetic metallic nanomaterials, nickel nanostructure materials are difficult to synthesize because they are easily oxidizable. Ball milling, electrodeposition, thermal plasma, polyol process, chemical vapour deposition (CVD), decomposition of organic-metallic precursors, chemical reduction in the liquid phase and many other methods (Degen and Macek, 1999; de Caro and Bradley, 1997; Steigerwald et al. 1988; Yurij et al., 1999; Zhang, et al., 2006) have been applied to obtain pure metallic nickel nanoparticles. Chemical reduction of cations from the solution of metal salts using strong reducing agents is the best way to prepare nickel nanostructure materials. 


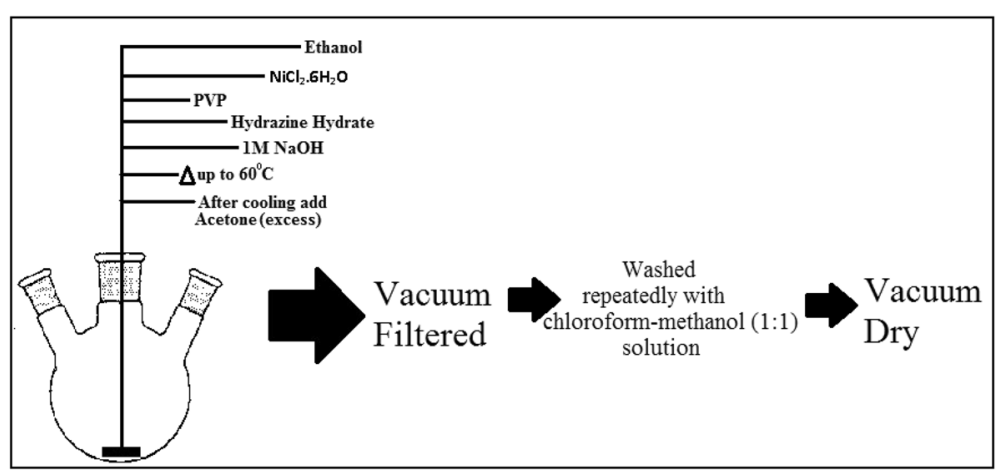

Fig. 1 Synthesis of Ni-PVP nanoparticles

Phthalocyanine reactive dyes are metallic complexes; mostly copper based gives turquoise colour shade. They are potentially mutagenic and have special toxicity concern because of metal $\mathrm{Cu}$ content. These dyes are not easily dischargeable and also have resistance towards oxidative degradation, which makes its decolourization a difficult task. They are highly water-soluble, shows resistance to adsorption and non-biodegradable under aerobic conditions resulting in permanent coloured effluent (Mathews et al., 2009).

Souza et al. (2007) have achieved $59 \%$ decolourization of Reactive Blue 21 (RB21) dye using horseradish peroxidise as oxidizer. Degradation of dye RB21 using soybean peroxidase as biocatalyst was evaluated by Marchis et al. (2011), and they achieved approximately $95-96 \%$ decolourization at $\mathrm{pH} 3.0$ with $4 \mathrm{~h}$ treatment time.

In this current work, the problem of agglomeration of nanoparticles has been successfully approached. The colour removal of the dye solution was carried out by using chemically synthesized disperse nickel nanoparticles in a non-aqueous solution using polyvinyl pyrrolidone (PVP) as a stabilizer. The various parameters such as time, nanoparticle concentration, initial RB21 dye concentration and $\mathrm{pH}$ were studied. Addition to colour removal, the effect of presence of salt and alkali in the dye solution and chemical oxygen demand (COD) reduction was also investigated.

\section{Methods}

\section{Chemicals}

C. I. Reactive Blue 21 was purchased from Colourtex Industries Limited, Mumbai. Nickel chloride $\left(\mathrm{NiCl}_{2} \cdot 6 \mathrm{H}_{2} \mathrm{O}\right.$, $\geq 98 \%$ ), hydrazine hydrate $\left(\mathrm{N}_{2} \mathrm{H}_{4} \cdot \mathrm{H}_{2} \mathrm{O}\right.$ molecular weight 50.06), acetone (molecular weight 58.08, $99 \%$ ), polyvinyl pyrrolidone (PVP K-30), sodium hydroxide $(\mathrm{NaOH}$, molecular weight 40), acetic acid, ethanol (99.7\%), chloroform, methanol, soda ash and Glauber's salt were supplied by S D Fine-Chem Limited (SDFCL, Mumbai).

\section{Synthesis of Ni-PVP nanoparticles}

Synthesis of the Ni-PVP nanoparticles was carried out as per the procedure discussed in a previously published article by Kale et al. (2014). $3.3-\mathrm{mM}$ solution of $\mathrm{NiCl}_{2} \cdot 6 \mathrm{H}_{2} \mathrm{O}$ was prepared in 200-mL ethanol and was added to a 500$\mathrm{mL}$ round bottom flask at room temperature. $0.125 \mathrm{~g}$ of PVP was then added to this solution and was stirred until complete dissolution of PVP. Hydrazine hydrate was further added, followed by $1 \mathrm{M} \mathrm{NaOH}$ under constant magnetic stirring. The solution was heated at $60{ }^{\circ} \mathrm{C}$ with stirring until the solution turned black. When hydrazine hydrate reacts with nickel ion, it releases nitrogen gas; hence, no additional nitrogen atmosphere was needed during synthesis. The scheme of the nanoparticle synthesis is shown in Fig. 1. During formation of nickel nucleus, the hydrophobic part of PVP molecules gets attached to nickel nucleolus reducing its surface energy and preventing its agglomeration (Gao et al., 2001). The solution was then cooled at ambient temperature. After the solution is cooled, acetone was added to precipitate out the nanoparticles. The solution was vacuum filtered, and particles were washed repeatedly with chloroform-methanol (1:1) solution. Synthesis of nickel nanoparticles without addition of

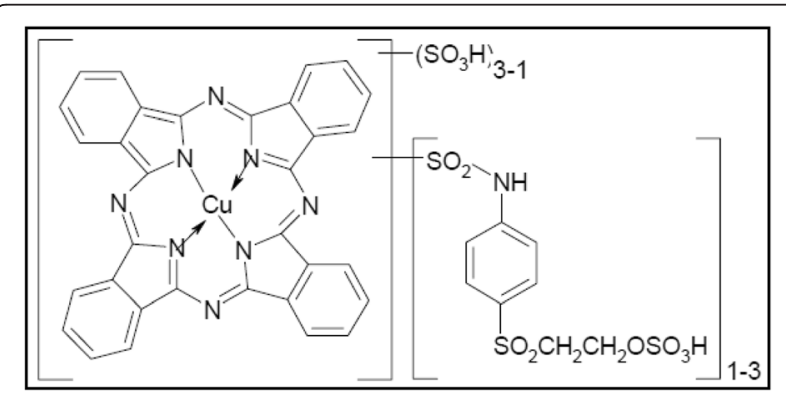

Fig. 2 Chemical structure of C. I. Reactive Blue 21 


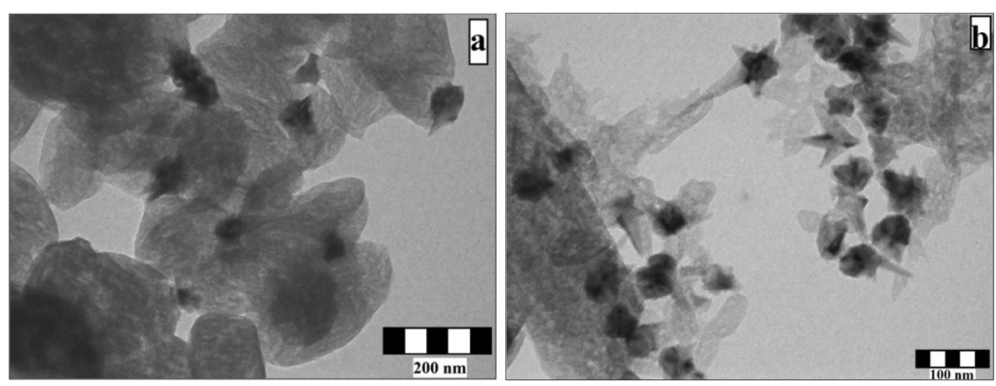

Fig. 3 TEM image of Ni-nanoparticles $\mathbf{a}$ without PVP and $\mathbf{b}$ with PVP

PVP was done in the same way. The reaction can be described by the following equation (Kalwar et al., 2014):

$$
2 \mathrm{Ni}^{2+}+\mathrm{N}_{2} \mathrm{H}_{4}+4 \mathrm{OH}^{-} \rightarrow 2 \mathrm{Ni}+\mathrm{N}_{2(\mathrm{~g})}+4 \mathrm{H}_{2} \mathrm{O}
$$

\section{Characterization of nanoparticles}

The size and morphology of the nanoparticles was estimated using transmission electron microscope (TEM) (Model CM 200, Philips) operated at an accelerating voltage of $200 \mathrm{kV}$. The mean diameter of the prepared Ni-PVP nanoparticles was determined using a laser light scattering particle size analyzer (SALD 7500 nano, Shimadzu, Japan). Powder X-ray diffraction (XRD) was recorded on Simadzu XRD-6100.

\section{Batch decolourization studies}

RB21 dye was selected due to the fact that it has complex structure with less \% exhaustion i.e. more unexhaust dye is in drained effluent which is not easily dischargeable. The structure of the dye is shown in Fig. 2. Dye stock solutions of different concentrations were prepared in deionized water, and decolourization experiments were performed in an open batch system at room temperature, $28 \pm 2{ }^{\circ} \mathrm{C}$. Dye solutions were stirred using a shaker machine (Rossari Labtech, Mumbai) at a speed of $70 \mathrm{rpm}$ to keep the nanoparticle powder suspended. Samples were withdrawn at fixed intervals of time and were subsequently centrifuged for $5 \mathrm{~min}$ at $3000 \mathrm{rpm}$. The clear solution was then pipetted out, and the rate of decolourization was measured by the absorbance at maximum wavelength $(622.4 \mathrm{~nm})$ using UV-VIS spectrophotometer (UV-VIS 8500, TECHCOMP Limited, Hong Kong). The percentage of dye decolourization was found out from calibration curve of the dye solution, using different dye concentrations and measuring its absorbance at $622.4 \mathrm{~nm}$. \% Decolourization was calculated as per the following equation:

\footnotetext{
$\%$ Decolourization $=\frac{(\text { initial concentration }- \text { final concentration })}{\text { Initial concentration }} \times 100$
}

The presence of degradation products on the nanoparticles was identified using FT-IR 8400S (CE), Shimadzu, Japan.

COD was measured using USEPA-approved dichromate COD method using Hach DRB digester and analysis with DR 900 colorimeter, USA.

\section{Results and discussion \\ Nanoparticle characterization}

The structure and morphology of nickel nanoparticles can be seen from Fig. 3. When dispersing agent was not added, agglomerated nanoparticles having size $29-243 \mathrm{~nm}$ were obtained in self-assembled flower-like structures (Fig. 3a). But when dispersing agent i.e. PVP was added during synthesis, Ni nanoparticles were well dispersed within the PVP matrix. And particle size reduces to 20-44 nm (Fig. 3b).

The XRD of the synthesized Ni particles is shown in Fig. 4 having peaks at Theta-2Theta value of $15.08^{\circ}$, $22.12^{\circ}, 31.22^{\circ}, 33.35^{\circ}$ and $51.06^{\circ}$ confirming the presence of $\mathrm{Ni}(0)$ nanoparticle (Sulekh et al. 2014).

The particle size distribution of Ni-PVP nanoparticles as determined on laser light scattering particle size analyzer shows that the particle size is $112 \mathrm{~nm}$ (Fig. 5). We observed narrow particle size range and stable

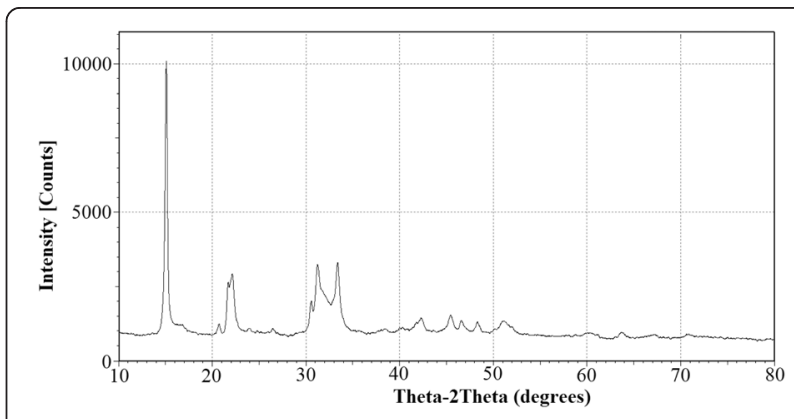

Fig. 4 XRD patterns of PVP stabilized Ni-nanoparticles 


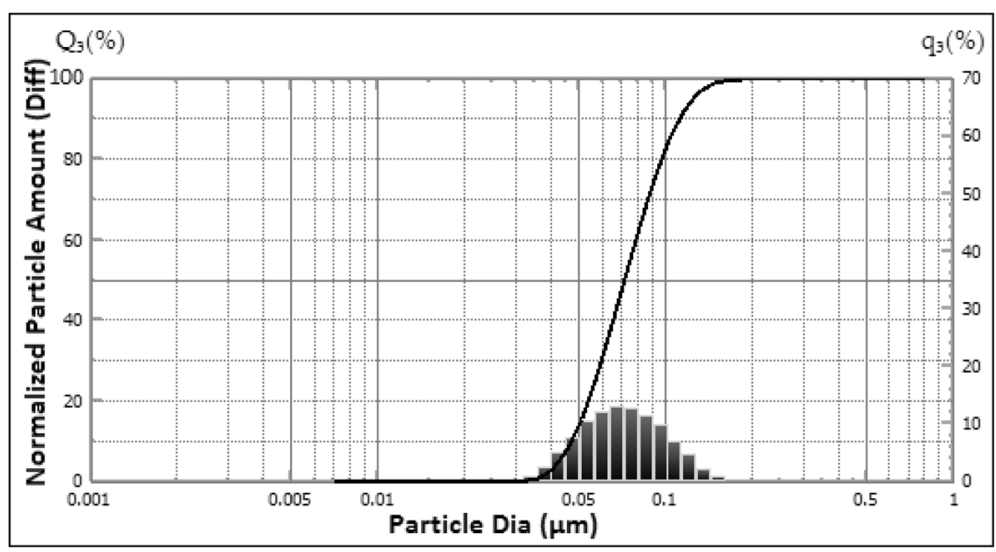

Fig. 5 Particle size analysis for Ni-PVP nanoparticles

dispersion of nano-Ni particles when PVP is used as stabilizer; these particles are further taken for the dye decolourization study.

\section{Dye decolourization}

The effect of time on \% decolourization of dye $(100 \mathrm{mg} / \mathrm{L})$ at different nanoparticle concentrations is shown in Fig. 6. The plot proves that as the concentration of nanoparticles was increased from 0.5 to $1.5 \mathrm{~g} / \mathrm{L}$, the \% decolourization also increased up to $98.97 \%$. For the same concentration of nanoparticles taken, \% decolourization increased with treatment time. Thus, maximum decolourization was seen at 120 min compared to lesser duration of treatment time.

It is but obvious that the more number of nanoparticles, the more is the availability of catalyst for attacking the chromophoric system of the dye. Similarly, with the

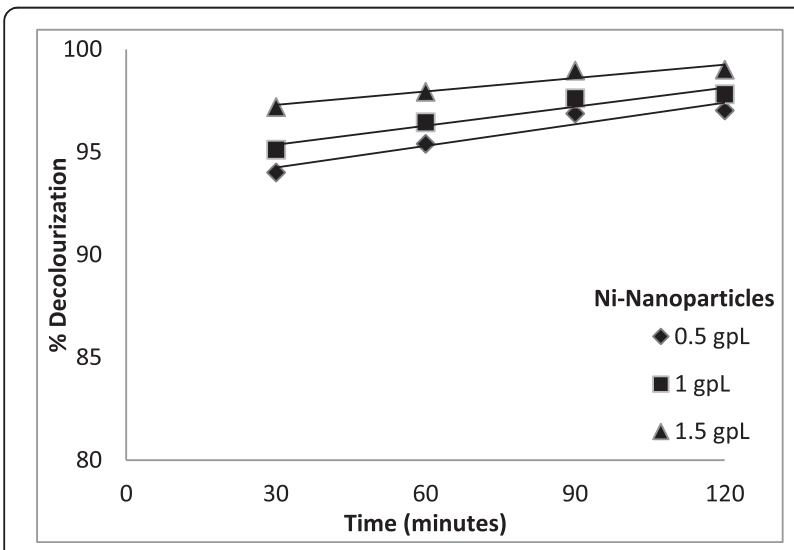

Fig. 6 Effect of time on \% decolourization of dye (100 mgpl) with nanoparticle concentration increase in duration of treatment, the more time is given for the reaction of dye decolourization. In Fig. 7, one can actually see the decolourization progress.

\section{Effect of initial dye concentration}

It can be seen from Fig. 8 that as the initial dye concentration taken for the study was increased from 100 to 200 to $300 \mathrm{mg} / \mathrm{L}$, the decolourization efficiency got decreased for the same amount of nanoparticle concentration. However, this difference is insignificant as the percentage decolourization was always between 96 and $99 \%$ for all the dye concentration taken.

The rest of the dye decolourization study was performed using $1.5 \mathrm{~g} / \mathrm{L}$ nanoparticle by taking $100 \mathrm{mg} / \mathrm{L}$ of the dye for $120 \mathrm{~min}$.

Figure 9 shows the absorbance spectrum of the dye solution before and after decolourization. It can be clearly seen that the absorbance of the dye solution has drastically reduced after decolourization with the characteristic peaks at maximum wavelength $(622.4 \mathrm{~nm})$ disappearing completely (Nath et al. 2007).

\section{Effect of $\mathrm{pH}$}

The $\mathrm{pH}$ of the aqueous solution is a complex parameter since it is related to the ionization state of the nanoparticle surface and that of the reactants and products such as acids and amines. In this work, we studied the effect of $\mathrm{pH}$ on dye degradation in the range of $2-7$ (Bokare et al., 2008). Figure 10 shows decolouration of the dye at different $\mathrm{pH}$ values. It can be seen that maximum \% decolourization was observed at pH 7 (99.01\% in $120 \mathrm{~min})$.

\section{Effect of alkali}

Reactive dyeing requires salt and alkali for good exhaustion of dye onto substrate. The effect of decolourization 


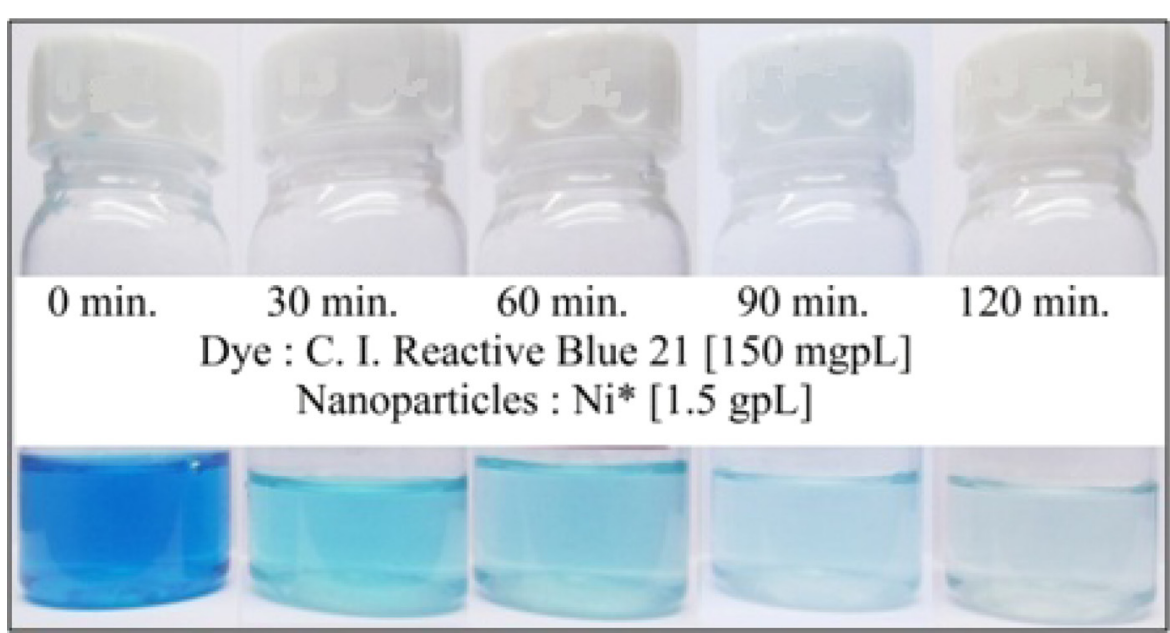

Fig. 7 Decolourization progress at different time intervals

using nanoparticle was thus studied in the presence of salt and alkali.

Twenty grams per litre of soda ash was added in the dye solution which increased the $\mathrm{pH}$ of solution to 11.3. The $\mathrm{pH}$ was brought down to the value of 7 by addition of acetic acid, and then \% decolourization study was done.

From Fig. 11, it can be seen that when soda ash is added in dye solution, \% decolourization was reduced from 98.09 to $68.09 \%$. After adjusting $\mathrm{pH}$ to basic condition, the decolourization rate of nanoparticles was found to be decelerated because the oxide precipitated onto the surface occupying the active sites, soon terminating the reaction (Mu et al. 2004).

\section{Effect of salt and alkali}

Figure 12 shows the combined effect of soda ash $(20 \mathrm{~g} / \mathrm{L})$ and Glauber's salt (40 g/L) addition on \% decolourization.

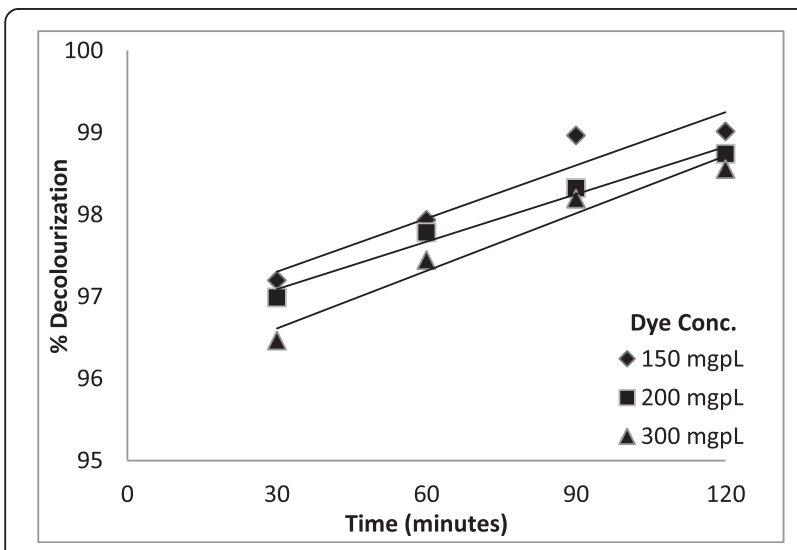

Fig. 8 Effect of initial dye concentration on \% decolourization using nanoparticles $(1.5 \mathrm{gpl})$ for $120 \mathrm{~min}$
It was found that \% decolourization efficiency reduced from 98.1 to 65.09 \% when both soda ash and Glauber's salt were present in the dye solution. This could be because of oxide formation on the surface of these nanoparticles reducing its reduction capacity.

\section{FT-IR measurements}

After $120 \mathrm{~min}$ of decolourization reaction, particulate materials which were nothing but nanoparticles were collected by centrifugation and removed from the supernatant solution. Vacuum drying of the collected particles was done at $60{ }^{\circ} \mathrm{C}$ for $6 \mathrm{~h}$ and was further characterized by FT-IR spectroscopy. By FTIR technique, we can identify the groups that got

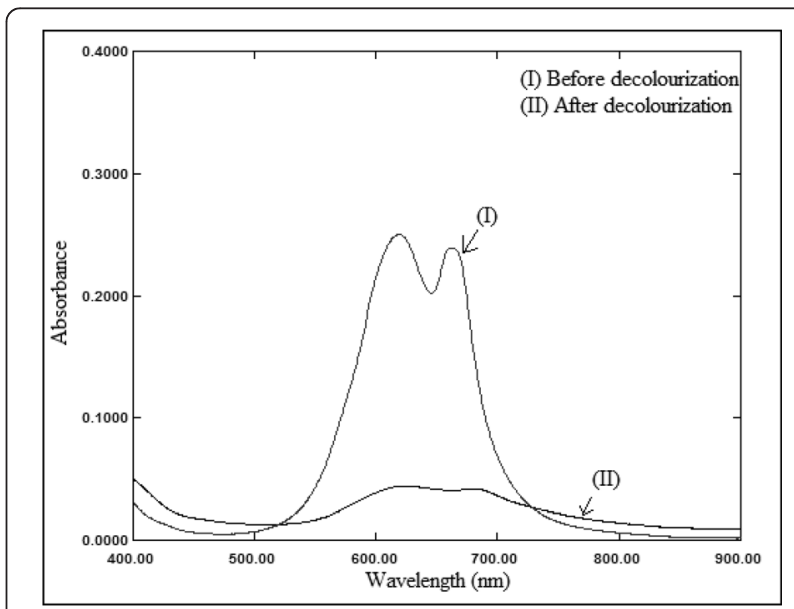

Fig. 9 UV-visible spectra recorded before and after decolourization of RB21 


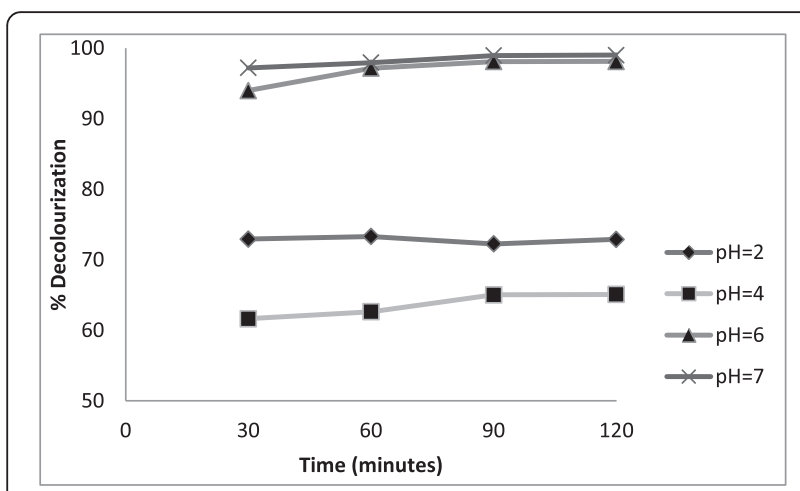

Fig. 10 Effect of $\mathrm{pH}$ variation on \% decolouration with nanoparticles (1.5 gpl) and dye (100 mgpl) for $120 \mathrm{~min}$

absorbed on the Ni-PVP nanoparticle surface after degradation of dye. The infrared spectra of nanoparticles before and after the decolourization process were recorded in the range of $4000-400 \mathrm{~cm}^{-1}$ on a FT-IR-8400S, Shimadzu (Fig. 13). As compared with the original Ni-PVP nanoparticles, some new bands were found on the Ni-PVP nanoparticles after decolourization including vibrations at $3282 \mathrm{~cm}^{-1}(\mathrm{~N}-\mathrm{H}$ bending), $3228 \mathrm{~cm}^{-1}$ ( $-\mathrm{CH}_{2}$ - bending), $1604 \mathrm{~cm}^{-1}$ ( $-\mathrm{C}=\mathrm{O}$ - bending), $1164 \mathrm{~cm}^{-1}\left(-\mathrm{SO}_{3}\right.$ bending) and $979 \mathrm{~cm}^{-1}(-\mathrm{C}-\mathrm{H}-$ bending), respectively. Thus, some amount of degraded product got attached on the surface of the nanoparticles (Dizge et al., 2008).

\section{COD reduction}

Dye reduction results reported in this study were based on the spectrophotometric analysis of the dye solutions. But the spectrophotometric evaluation cannot be interrelated to reduction of $C O D$ as we wanted to know the effect of presence of nanoparticles on COD value of dye

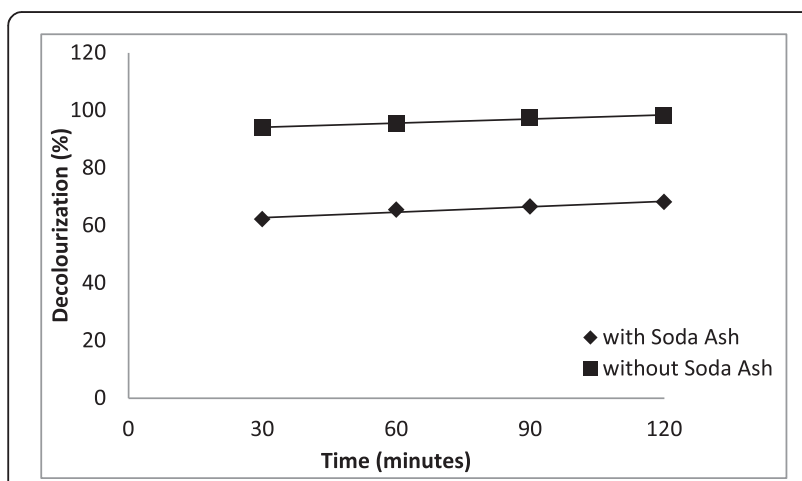

Fig. 11 Effect of soda ash (20 gpl) addition on \% decolouration with nanoparticles (1.5 gpl) and dye (100 mgpl)

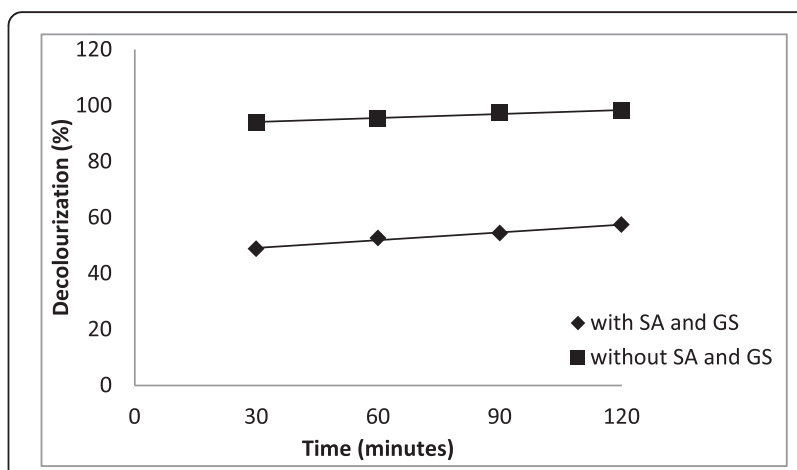

Fig. 12 Effect of soda ash (SA) $20 \mathrm{gpl}$ and Glauber's salt (GS) $40 \mathrm{gpl}$ addition on \% decolouration with nanoparticles (1.5 gpl) and dye (100 mgpl)

effluent (Golder et al., 2005). COD value for treated effluent was $61 \mathrm{ppm}$ while the same for untreated one was $125 \mathrm{ppm}$. It can be inferred that Ni-PVP nanoparticles not only eliminates the colour from the effluent but also reduces the COD indicating degradation of the dye.

\section{Conclusions}

PVP stabilized nickel nanoparticles were successfully synthesized and used for decolourization of recalcitrant dye effluent. These nanoparticles gave decolourization efficiency of $98.97 \%$ at optimized condition. Decolourization also led to the reduction in COD of the effluent. Both of these were achieved with minimum generation of sludge which is a major problem in case of conventional methods which are used for decolourization such as coagulation and flocculation.

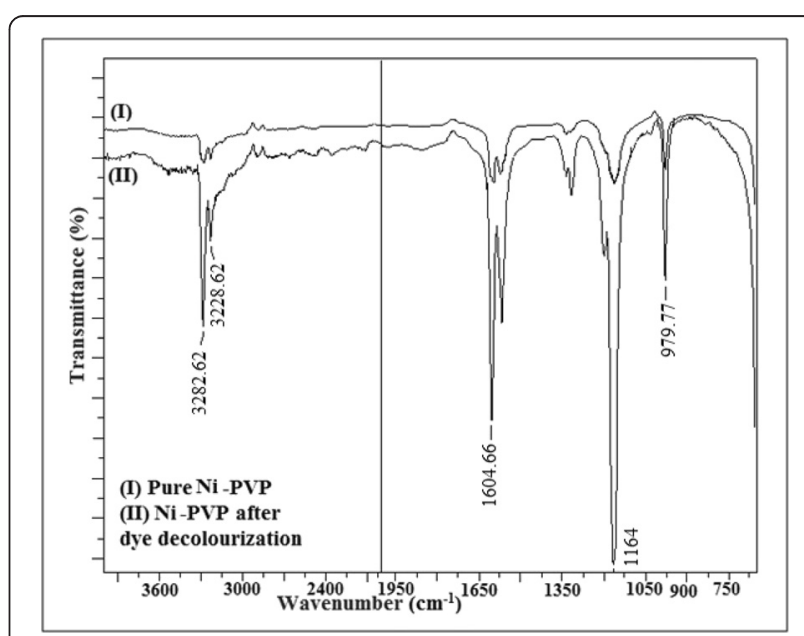

Fig. 13 FT-IR spectra of nanoparticle and dye-loaded nanoparticle sample 


\section{Competing interests}

The authors declare that they have no competing interests.

\section{Authors' contributions}

RDK guided in carrying out the practical work (synthesis, optimization, characterization, testing etc.) and editing of the manuscript. PK carried out the complete research work including synthesis, optimization, characterization, application, testing etc. and drafting of the research paper. Both authors read and approved the final manuscript.

\section{Acknowledgements}

The authors would like to acknowledge DST-FIST programme of Indian government for providing the testing facilities and University Grants

Commission (UGC) for fellowship in successful completion of this research work.

Received: 29 December 2015 Accepted: 14 March 2016

Published online: 31 March 2016

\section{References}

Bokare, AD, Chikate, RC, Rode, CV, Paknikar, KM, (2008). Applied Catalysis B: Environmental, 79, 270-278

de Caro, D, \& Bradley, JS. (1997). Langmuir, 13, 3067-3069

Degen, A, \& Macek, J. (1999). Nanostructured Materials, 12, 225-228

Dizge, N, Aydiner, C, Demirbas, E, Kobya, M, Kara, S. (2008). Journal of Hazardous Materials, 150, 737-746

Gao, J, Guan, F, Zhao, Y, Yang, W, Ma, Y, Lu, X, Hou, J, Kang J. (2001). Materials Chemical and Physics, 71, 215

Ghanizadeh, GH, \& Asgari, G. (2009). Iranian Journal of Health and Environment, 2, 104-13

Golder, AK, Hridaya, N, Samanta, AN, Ray, S. (2005). Journal of Hazardous Materials B, 127, 134-140

Hergt, R, Dutz, S, Mülle, R, Zeisberger, M. (2006), Journal of Physics: Condensed Matter, 18, S2919

Kale, RD, Kane, P, Phulaware N. (2014) International Journal of Engineering Science and Innovative Technology, 3(2), 109-117

Kalwar, NH, Sirajuddin, Hallam KR. et al. (2013). Applied Catalysis A, 453, 54-59

Kalwar, NH, Sirajuddin, Soomro, RA, Sherazi, STH, Hallam, KR, Khaskheli, AR. (2014). Synthesis and characterization of highly efficient nickel nanocatalysts and their use indegradation of organic dyes. International Journal of Metals, 20, 10-14.

Lai, TL, Wang, WF, Shu, YY, Liu, YT, Wang, CB. (2007). Journal of Molecular Catalysis A: Chemical, 273, 303-9

Marchis, T, Avetta, P, Bianco-Prevot, A, Fabbri, D, Viscardi, G, Laurenti, E. (2011). Journal of Inorganic Biochemistry, 105, 321-327

Mathews, RD, Bottomley, LASG, Pavlostathis, P. (2009). Desalination, 248 $816-825$

Mu, Y, Yu, HQ, Zhang, SJ, Zheng, JC. (2004). Journal of Chemical Technology and Biotechnology, 79, 1429-143

Naoki, T. (2008). Macromol. Symp., 270, 27-39

Nateghi R, Bonyadinejad GR, Amin MM, Mohammadi H. (2012). Decolorization of synthetic wastewaters by nickel oxide nanoparticle. International Journal of Environmental Health Engineering, 1(1), DOl:10.4103/2277-9183.98384.

Nath, S, Praharaj, S, Panigrahi, S, Basu, S, Pal, T. (2007). Current Science, 92(6), 786-790

Saadatjou, N, Rasoulifard, MH, Heidari, A. (2008) Journal of Color Science and Technology, 2, 221-6

Sakulchaicharoen, NA, O'Carroll, DMA, Herrera, JEB. (2010), Journal of Contaminant Hydrology, 118(3-4), 117-127

Shen, L, Laibinis, PE, Hatton, TA. (1999). Langmuir, 15, 447

Song, Z, Chen, L, Huand, J, Richards, R. (2009). Nanotechnology, 9, 2-10

Souza, SMAGU, Forgiarini, E, Souza, AAU. (2007). Journal of Hazardous Materials, $147,1073-1078$

Steigerwald, ML, Alivisatos, AP, Gibson, JM, Harris, TD, Kortan, R, Muller, A.J, Thayer, AM, Duncan, TM, Douglass, DC, Brus, LE. (1988) Journal of the American Chemical Society, 110, 3046-3050

Sulekh, C, Kumar, A, Tomar, PK. (2014). Journal of Saudi Chemical Society, 18 437-442

Tagar, ZA, Sirajuddin, Memon N. et al. (2012). Pakistan Journal of Analytical and Environmental Chemistry, 13(1), 70

Wang, HC, Chang, SH, Hung, PC, Hwang, JF, Chang, MB. (2008). Chemosphere, 71, 388-97
Yurij, K, Asuncion, F, Cristina, RT, Juan, C, Pilar, P, Ruslan, P, Aharon, G. (1999). Chemistry of Materials, 11, 1331-1335

Zhang, HT, Wu, G, Chen, XH, Qiu, XG. (2006) Materials Research Bulletin, 41, 495-501

Zollinger, H. (1987). Colour chemistry-synthesis, properties and application of organic dyes and pigments. NewYork: VCH.

\section{Submit your manuscript to a SpringerOpen ${ }^{\circ}$ journal and benefit from:}

- Convenient online submission

- Rigorous peer review

- Immediate publication on acceptance

- Open access: articles freely available online

- High visibility within the field

- Retaining the copyright to your article

Submit your next manuscript at $>$ springeropen.com 